\title{
Fever of unknown origin (FUO) on a land on cross-roads between Asia and Europa; a multicenter study from Turkey
} \author{
Sukran Kose ${ }^{15}$ \\ ${ }^{1}$ Sultan Abdülhamid Han Training and Research Hospital \\ ${ }^{2}$ Diyarbakir Gazi Yasargil Training and Research Hospital \\ ${ }^{3}$ Ankara Gulhane Egitim ve Arastirma Hastanesi \\ ${ }^{4}$ İstanbul Haydarpaşa Numune Eğitim ve Araştırma Hastanesi \\ ${ }^{5}$ Istanbul Dr Lufti Kirdar Kartal Egitim ve Arastirma Hastanesi \\ ${ }^{6}$ Antalya Egitim ve Arastirma Hastanesi \\ ${ }^{7}$ Tepecik Egitim ve Arastirma Hastanesi Kliniklerimiz \\ ${ }^{8}$ Sanliurfa Mehmet Akif Inan Training and Research Hospital \\ ${ }^{9}$ Bursa Yuksek Ihtisas Training and Research Hospital \\ ${ }^{10}$ Izmir Bozyaka Training and Research Hospital \\ ${ }^{11}$ Harran University \\ ${ }^{12}$ Fatih Sultan Mehmet Training and Research Hospital \\ ${ }^{13}$ Adana Numune Egitim ve Arastirma Hastanesi \\ ${ }^{14}$ Sisli Hamidiye Etfal Training and Research Hospital \\ ${ }^{15}$ Tepecik Training and Research Hospital Clinics
}

ERCAN YENILMEZ ${ }^{1}$, Deniz Kakalicoglu ${ }^{1}$, Fatma Bozkurt ${ }^{2}$, Mine Filiz $^{3}$, Aysegul Akkol Camurcu $^{4}$, Elif Ozge Damar Midik ${ }^{5}$, Hande Berk Cam $^{6}$, Eren Arkali ${ }^{7}$, Seval Bilgic Atli ${ }^{2}$, Ahmet Sahin ${ }^{8}$, Sibel Yorulmaz Goktas ${ }^{9}$, Halil Erkan ${ }^{10}$, MEHMET REŞAT CEYLAN ${ }^{11}$, Merve Kacar Eker ${ }^{12}$, Hava Kaya ${ }^{13}$, Ersin Tural ${ }^{1}$, Illyas Dökmetaş ${ }^{14}$, Levent Gorenek ${ }^{1}$, and

November 11, 2020

\begin{abstract}
Aims: The differential diagnosis of Fever of Unknown Origin (FUO) is still a major clinical challenge despite the advances in diagnostic procedures. In this multicenter study, we aimed to reveal FUO etiology and factors influencing the final diagnosis of FUO in Turkey. Methods: A total of 214 patients with FUO between the years 2015-2019 from 13 tertiary training and research hospitals were retrospectively evaluated. Results: The etiologic distribution of FUO was infections (44.9\%), malignancies (15.42\%), autoimmune/inflammatory (11.68\%) diseases, miscellaneous diseases $(8.41 \%)$ and undiagnosed cases (19.62\%). Brucellosis (10.25\%), extrapulmonary tuberculosis (6.54\%) and infective endocarditis (6.54\%) were the most frequent three infective causes. Solid malignancies $(7.1 \%)$ and lymphoma (5.6\%), adult-onset still's disease (6.07\%) and thyroiditis $(5.14 \%)$ were other frequent diseases. The etiologic spectrum did not differ in elderly $(\mathrm{p}<0.05)$. Infections were less frequent in Western (34.62\%) compared to Eastern regions of Turkey (60.71\%) ( $\mathrm{p}<0.001$, OR: 0.31, 95\% Cl: 0.19 to 0.60$)$. The ratio of undiagnosed etiology was significantly higher in elderly (p: 0.046, OR: $2.34,95 \% \mathrm{Cl}: 1.00$ to 5.48 ) and significantly lower in Western Turkey (p: 0.004, OR: 3.07, 95\% Cl: 1.39 to 6.71). Conclusion: Brucellosis, extrapulmonary tuberculosis and infective endocarditis remain to be the most frequent infective causes of FUO in Turkey. Solid tumors and lymphomas, AOSD and thyroiditis are the other common diseases. The etiologic spectrum did not differ in elderly, on the other hand, infections were more common in Eastern Turkey. A considerable amount of etiology remained undiagnosed despite the state-of-the-art
\end{abstract}


technology in healthcare services.

\section{Hosted file}

FUO_Manuscript_-_IJCP.pdf available at https://authorea.com/users/374846/articles/492275fever-of-unknown-origin-fuo-on-a-land-on-cross-roads-between-asia-and-europa-amulticenter-study-from-turkey

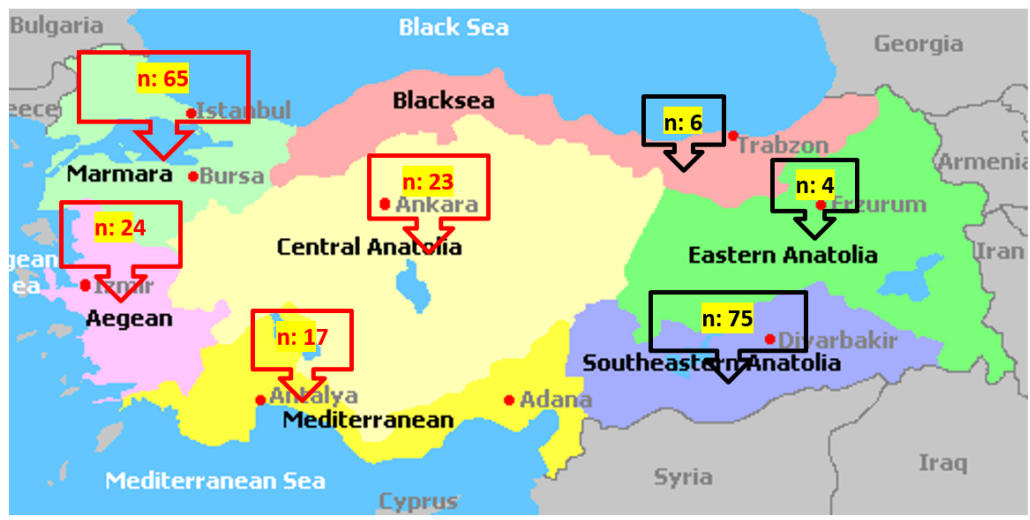

Figure 1. Regional distribution of patients in the study ( $\mathrm{n}: 214)$. Western Turkey (red color) includes Marmara, Aegean, Mediterranean and Central Anatolia Regions. Eastern Turkey (Black color) includes Black Sea, Eastern and Southeastern Anatolia Regions. 